\title{
Why Might Clinicians in Malawi not Offer HIV Testing to their Patients?
}

\author{
Corey Lau', Adamson S. Muula², Tilera Dzingomvera ${ }^{3}$, Gregory Horwitz ${ }^{4}$ and Humphreys Misiri ${ }^{5}$
}

\begin{abstract}
In order to identify reasons clinicians in Malawi might not offer HIV testing to patients, a cross-sectional descriptive postal census with telephone and fax follow-up was conducted. Proportions were calculated for each reason given for not offering HIV testing. Multiple logistic regression was used to determine whether responses differed by demographic characteristics. The response rate was $54.3 \%$. The five most common reasons for not offering HIV testing were: (1) inadequate training in HIV counselling (50.3\%); (2) perception that the patient is not ready (49.5\%); (3) no indication (35.6\%); (4) testing facilities unavailable (35.4\%); and (5) insufficient time (28.9\%). Differences in reasons for not offering HIV tests amongst clinician groups were few. Thus, development of one general programme based on common reasons identified in this study could be effective in increasing HIV testing rates. Further investigation of the identified reasons should be undertaken to facilitate programme development. (AfrJ Reprod Health 2005; 9[3]:41-50)
\end{abstract}

\section{RÉsumé}

Pourquoi les cliniciens malawiens ne pourraient-ils pas assurer le service du test pour le VIH à leurs patients? Afin d'identifier les raisons pour lesquelles les cliniciens malawiens ne pourraient pas assurer le service du test pour le VIH aux patients, nous avons fait un recensement postal descriptif traversal avec une suivie téléphonique et du fax. Les proportions ont été calculées pour chaque raison donnée pour ne pas assurer le test pour le VIH. A l'aide de la regression logique multiple, nous avons déterminé si les réponses variaient selon les caractéristiques démographiques. Le taux de réponse était de 54,3\%. Les cinq raisons les plus communes pour lesquelles le test pour le VIH n'est pas assuré étaient: 1) la formation inadéquate par rapport au service d'orientation concernant le VIH (50,3\%); 2) la perception du fait que le patient n'est pas prêt (49,5\%); 3) pas d'indication (35,6\%); 4) le manque d'équippement pour effectuer le test $(35,4 \%) ; 5)$ pas assez de temps $(28,9 \%)$. Il y a peu de différences parmi les raisons données par les groupes de cliniciens pour expliquer pourquoi ils n'assurent pas le test pour le VIH. Ainsi, l'élaboration d'un programme général qui est basé sur les raisons communes identifiées dans cette étude pourrait être efficace pour augmenter le taux du test pour le VIH. Il faut étudier davantage les raisons identifiées en vue de rendre plus facile l'élaboration des programmes. (Rev Afr Santé Reprod 2005; 9[3]:41-50)

Key Words: Patients, Clinicians, Testing, Offer

Division of AIDS, National Institute of Allergy and Infectious Disease, Bethesda, Maryland, USA. Department of Community Health, University of Malawi, College of Medicine, Blantyre, Malawi, Out-Patient Clinic, Blantyre Adventist Hospital, Blantyre,Malawi. Vision Center Laboratory, Salk. Institute for Biological Studies, La Jolla, Callifornia, US A. Department of Community Health, University of Malawi College of Medicine Blantyre, Malawi

Correspondence: Corey Lau, 10127 Asbourton Lane, Bethesda, MD 20817, Maryland, US A Email: chuenyenlau@hotmail.com

\section{Introduction}


42 African Journal of Reproductive Health

$\mathrm{HIV} / \mathrm{AIDS}$ is a major global health concern. Over 42 million people are estimated to be infected with the virus worldwide. Sub-Saharan Africa, where at least 29 million people were infected at the end of 2002 , has the highest prevalence. ${ }^{1}$

It is estimated that at least $14 \%$ of Malawi's adult (15-49-year-old) population is infected with $\mathrm{HIV}^{2}$ Concomitant food shortages and poverty serve to exacerbate this epidemic. Malawi is, therefore, amongst countries that have been hardest hit. ${ }^{3,4}$ For example, HIV infection is responsible for the upsurge in the number of tuberculosis (TB) cases, pneumonia, sepsis, Kaposi's sarcoma and other cancers in Malawi. ${ }^{5-7}$ Furthermore, mortality is higher amongst children with HIV-positive parents. ${ }^{8}$ Unfortunately, diagnosis of HIV usually occurs late in the disease, when symptoms and AIDS defining illnesses are already present.

Benefits of early HIV diagnosis have become increasingly apparent with recent treatment advances. ' A few years back, diagnosis of HIV sero-positivity resulted only in disheartenment due to lack of effective therapy. Even in the private sector where at least some could afford drugs, particularly anti-retroviral therapy (ART), the outlook for HIV positive persons was dismal. Presently, ART has been made more accessible at a number of private hospitals, and even at selected public health institutions. ${ }^{10}$ At the end of 2002, 1,220 patients in Malawi's public health sector were receiving ART (904 in Blantyre and Lilongwe, 316 in Chiradzulu). ${ }^{11}$ However, given the $14 \%$ infection rate and WHO estimate that at least $10 \%$ of infected individuals need ART, at least 165,000 people in Malawi are candidates for treatment.

The Ministry of Health and Population plans to increase accessibility to ART through the Global Fund for HIV/AIDS programmes. ${ }^{12}$ As part of its scale-up programme, the first national guidelines for the treatment of HIV/AIDS have recently been released. ${ }^{13}$ Other measures to improve ART availability are Church of Central
Africa Presbyterian (CCAP) Blantyre Synod Initiative through a donation from the Pittsburgh Presbytery and involvement by non-governmental organisations, for example, Medicins Sans Frontieres (MSF). ${ }^{14}$

At this time, Malawi's public health system offers HIV testing and ARV at Lilongwe Central Hospital and Queen Elizabeth Central Hospital. District-based operations in Thyolo and Chiradzulu, as well as select private institutions, also provide these services. ${ }^{15}$ In conjunction with increasing the availability of ART, efforts are being made to establish additional testing centres.

Studies suggest that worldwide screening levels for sexually transmitted diseases, including HIV, are well below practice guidelines. ${ }^{16,17}$ For example, a survey of members of the American Academy of Pediatrics found that $42.5 \%$ of pediatricians do not counsel pregnant women or mothers of newborns on HIV screening. ${ }^{18}$ Peters, et. al., reported that missed opportunities for perinatal HIV prevention contributed to more than half of the cases of HIV infected infants. ${ }^{19}$ However, implementation of an opt-out prenatal HIV testing policy results in dramatic increase in the number of females being tested for HIV infection. ${ }^{20}$ Furthermore, education of health-care providers has been shown to dramatically increase testing rates. ${ }^{21-23}$

Ethical dilemmas associated with HIV testing may prevent health-care workers from offering testing and may also inhibit patient acceptance of testing. ${ }^{24,25}$ In the United Sates, New Zealand and Zimbabwe, surveys have revealed several reasons physicians might not offer HIV testing to patients. These include perceived reluctance to be tested, lack of time, poor knowledge, insufficient support services, disinclination to inform a patient about positive sero-status, and fear of traumatising patients. ${ }^{26-28}$ However, HIV testing is a cost-effective approach for preventing HIV infection. ${ }^{29,30}$ In addition, routine screening is likely more cost-effective than testing based on medical history. ${ }^{31}$

Knowledge about HIV status informs pos- 
sible management options on the part of both patients and health-care workers. If clinicians do not offer HIV tests to their patients, the benefits of HIV sero-status knowledge may be forfeited. Furthermore, benefits of early diagnosis and treatment options such as highly active antiretroviral therapy (HAART) for HIV, cotrimoxazole prophylaxis against Pneumocystis carinï pneumonia and fluconazole for cryptococcal meningitis continue to increase. Since Malawi is so severely impacted by the HIV/AIDS epidemic and identification of infected persons is suboptimal, measures must be taken to increase HIV testing rates. Patient-clinician interactions are an invaluable but under-utilised opportunity for testing. In this study, clinicians registered with the Medical Council of Malawi were surveyed to identify their reasons for not offering HIV testing to their patients.

\section{Methods}

This was a cross-sectional descriptive postal survey with telephone and fax follow-up. All clinicians registered with the Medical Council of Malawi were recruited to participate in this study. These included specialists, general practitioners, dentists, clinical officers and medical assistants from both public and private practices. Professional categories were distinguished by their level of training — specialists had completed a residency in their field; while the general practitioners had completed an eighteen-month postgraduate internship. Clinical officers had completed three years of schooling and a one-year internship; while medical assistants had completed two years of schooling. Clinical officers and medical assistants comprised the largest groups of clinicians in Malawi. ${ }^{32}$

As the annually published Medical Council of Malawi registry may be incomplete, clinicians' names were also obtained from district and mission hospitals and survey questionnaires mailed to them. Clinicians who were out of the country during the study period or retired were excluded from the census. A total of 1,007 clinicians, out of which 964 met the eligibility criteria, were identified via the Medical Council of Malawi registry and hospital reports.

Instruments designed by the authors were used to assess reasons for not offering HIV testing. All surveys included instructions to print clearly and asked several basic demographic questions. Following the demographic questions, participants were asked to tick choices corresponding to and/or write their reasons for not offering HIV testing. They were also asked whether they asked their patients if they would like to be tested for HIV. Ethical clearance was obtained from the College of Medicine Research and Ethics Committee (COMREC).

Postal survey techniques with telephone and fax follow-up were used to collect information from the clinicians. Surveys were mailed to them in May 2003. A pre-addressed stamped envelope was included in the mail to facilitate return of responses by the respondents. After one month, non-respondents were contacted by telephone. Telephone numbers listed in the Medical Council of Malawi registry, district health offices and in the Malawi Telecommunications Limited directory were used. If the clinician was unable to complete the survey via telephone, the survey was faxed to him/her and returned by fax to Blantyre Adventist Hospital after completion.

Survey data were entered into a Microsoft Excel spreadsheet. To account for use of different wording in the written response section, responses were grouped according to reason, for purposes of analysis.

As the various clinical cadres did not respond in the same distribution as represented in the medical register, population weighting, with clinicians listed by the Medical Council of Malawi as the standard, was used to evaluate the effect of non-response related to profession. ${ }^{33}$ Proportions were calculated for each listed reason for not offering HIV testing to patients. Multiple logistic regression techniques were used to 
44 African Journal of Reproductive Health

determine whether responses differed by respondents' age, gender, citizenship or profession. ${ }^{34}$ The fitted model was of the form: $\log [\mathrm{p} /(1-\mathrm{p})]$ $=\beta_{0}+\beta_{1}$ (age) $+\beta_{2}$ (gender) $+\beta_{3}$ (citizenship) + $\beta_{4}$ (specialist) $+\beta_{5}$ (general practitioner $)+\beta_{6}$ (medical assistant $)+\beta_{7}$ (dentist $)+\beta_{8}$ (other profession).

Each of the 16 reasons for not offering HIV testing was modelled independently. Clinical officers comprised the largest proportion and were, therefore, used as the referent group. S-plus statistical package was used for analysis. ${ }^{35}$ Statistical significance was assessed with likelihood ratio tests. A p-value $<0.05$ was considered statistically significant.

\section{Results}

Five hundred and twenty-three of 964 clinicians $(54.3 \%)$ responded to the postal survey. Four hundred and thirty-two responded to the initial mailing; while 91 responded after telephone follow-up. Demographic characteristics of respondents are shown in Table 1. Average age of respondents was $43.6 \pm 13.0$ years (mean \pm standard deviation). Table 2 shows the reported professions of respondents and profession distribution from the registry of the Medical Council of Malawi. There was a difference in distribution of professions between respondents and the surveyed population; medical assistants were underrepresented while clinical officers were over-represented in the sample.

\section{Table 1 Demographic Factors of Respondents}

\begin{tabular}{lccc}
\hline Factor & Sample size & Number & \% of sample \\
\hline Gender (male) & 524 & 478 & 91.22 \\
Citizenship (Malawian) & 523 & 477 & 91.20 \\
Private practice (yes) & 516 & 203 & 39.34 \\
Palliative care training (yes) & 475 & 194 & 40.84 \\
HIV testing available (yes) & 520 & 288 & 55.38 \\
Antiretroviral therapy available (yes) & 521 & 117 & 22.46 \\
Trained HIV counsellor present (yes) & 515 & 343 & 66.47 \\
Home care available (yes) & 515 & 232 & 45.05 \\
\hline
\end{tabular}

Sample sizes vary because some respondents did not provide information on some factors.

\section{Table 2 Professional Categories of Respondents}

\begin{tabular}{lcc}
\hline Profession & Respondents (\%) & Population (\%) \\
\hline Clinical officer & $195(37.28)$ & $294(29.94)$ \\
Medical assistant & $177(33.84)$ & $455(46.33)$ \\
General practitioner & $75(14.34)$ & $146(14.87)$ \\
Specialist* & $39(7.45)$ & $62(6.31)$ \\
Dentist & $7(1.34)$ & $25(2.55)$ \\
Other & $30(5.74)$ & $0(0.00)$ \\
\hline
\end{tabular}

*Specialist includes surgery, obstetrics/gynaecology, internal medicine, paediatrics and psychiatry. 
Reasons given for not offering HIV testing to patients are shown in Table 3. In addition to the eleven suggested reasons, five other reasons were included based on written responses. These were (1) no facility available; (2) no ARV available; (3) non-conducive circumstances (e.g., communi-cation barriers, lack of privacy in the clinic); (4) logistical difficulties (e.g., testing centre is too far, results take too long); and (5) cost of testing and therapy.

Population weighting by profession did not affect relative order of reasons provided. Population weighting by age was not performed because difference in mean ages between the sample and surveyed population was 3.3 years, which is relatively small.

Table 4 shows odds ratios with $95 \%$ confidence intervals for each predictor in the model on reasons clinicians gave for not offering HIV tests to their patients.

\section{Discussion}

Amongst clinicians in Malawi, reasons for not offering HIV testing to patients varied greatly. The most common reasons clinicians in Malawi gave for not offering HIV testing to their patients were that they were not adequately trained in HIV counselling (50.3\%); perception that the patient is not ready to be tested $(49.5 \%)$; there is no indication for testing (35.6\%); testing facilities are unavailable (35.4\%); and that there is insufficient time for testing $(28.9 \%)$. Other reasons were given by less than $20 \%$ of clinicians.

Amongst these five most common reasons, inadequate training in HIV counselling, patient not ready to be tested, and lack of testing facility showed statistical significant difference amongst clinician subgroups. Specifically, medical assistants were more likely to give the reasons of not being trained in HIV counselling $(95 \% \mathrm{CI}=(2.27$,

\section{Table 3 Reasons for not Offering HIV Testing to Patients}

\begin{tabular}{lc}
\hline Response & Number Reporting (\%) \\
\hline Not a trained counsellor & $263(50.29)$ \\
Patient not ready & $259(49.52)$ \\
No indication for testing & $186(35.56)$ \\
No facility available & $185(35.37)$ \\
Not enough time & $151(28.87)$ \\
Patient personally known & $92(17.59)$ \\
Circumstances & $83(15.87)$ \\
First clinical encounter & $61(11.66)$ \\
Poor prognosis & $56(10.71)$ \\
No HAART available & $44(8.41)$ \\
Guardian present & $39(7.46)$ \\
Logistics of testing & $29(5.54)$ \\
Patient's age & $28(5.34)$ \\
Not involved in care & $25(4.78)$ \\
Cost of testing/therapy & $25(4.78)$ \\
Forgot to ask & $17(3.25)$ \\
\hline
\end{tabular}

Total sample size is 523. Values are not population weighted. The sum of response percentages exceeds $100 \%$ because respondents were allowed to provide multiple reasons. 


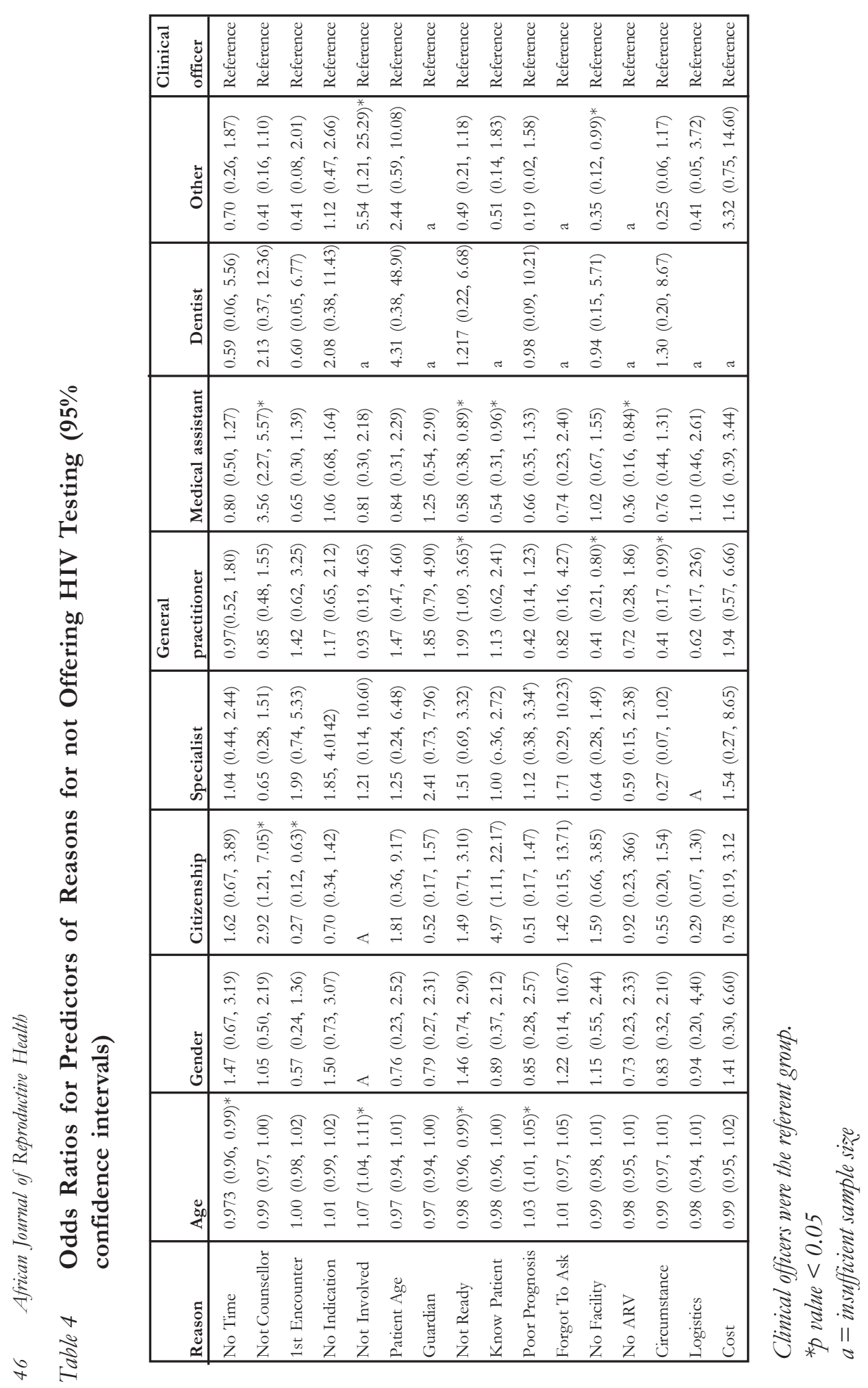


5.58); $\mathrm{p}<0.0001)$ and less likely to give the reason of patient not being ready to be tested $(95 \% \mathrm{CI}$ $=(0.38,0.89) ; \mathrm{p}<0.05)$; general practitioners were less likely to give reasons of no testing facility $(95 \% \mathrm{CI}=(0.21,0.80) ; \mathrm{p}<0.05)$ and more likely to give reason of patient not ready to be tested $(95 \% \mathrm{CI}=(1.08,3.65) ; \mathrm{p}<0.05)$. Clinicians who indicated other profession were less likely to give lack of testing facility as reason $(95 \%$ $\mathrm{CI}=(0.13,0.99) ; \mathrm{p}<0.05)$. Thus, common reasons clinicians might not offer HIV testing to patients differed slightly amongst professional groups. The strongest correlation was shown between medical assistants, who constituted $46.3 \%$ of Malawi's clinicians and not being trained in HIV counselling, the most common reason given by the all clinicians.

Age is also significantly correlated with two of the five most common reasons for not offering HIV testing to patients (patient not ready to be tested, no time for testing). It is possible that age is a proxy for number of years in practice. Regardless, the odds ratios were all very close to 1.0 (range 0.9370-1.0724) even though age showed statistically significant correlations with several reasons. Thus, common reasons clinicians might not offer HIV testing to patients can be considered to be fairly homogeneous across age groups.

Given that common reasons for not offering HIV testing to patients differed only slightly amongst clinicians and age groups, it is reasonable to treat clinicians as one large group when developing interventions based on these reasons. It would also be most practical to develop a collective intervention for all clinicians in Malawi, rather than different interventions for different clinician groups. The intervention should focus on the most common reasons provided by the entire group of clinicians.

In this study, the most common reason for not offering HIV testing to patients was inadequate training in HIV counselling. However, nurses trained in Malawi, clinical officers and medical assistants usually attend a six-week HIV counselling course. Specialists, especially those exposed to international training, study HIV in medical school and manage HIV cases during residency. Despite this training, clinicians in Malawi felt that they had not been adequately trained in HIV counselling. Thus, medical education programmes may need to modify their approach to HIV counselling. For example, experiential training would allow budding clinicians to become comfortable in practical application of their knowledge.

Additionally, practising clinicians may be periodically required to undertake continuing medical education in HIV counselling. While formal continuing medical education is not compulsory in Malawi, the current system of hospital-based conferences could be adapted. More detailed information on the specific aspects of training that clinicians feel are lacking must be obtained before specific educational modules can be designed.

After inadequate training, the second and third most common reasons for not offering HIV testing are the perception that patients were not ready and no indication for testing respectively. In these cases, lowering the testing threshold might help minimise the number of patients who remain untested. Although clinical judgment should not be disregarded, it is possible that clinicians have an unnecessarily high threshold for believing a patient's readiness or indication for testing. Considering that approximately one in six adult Malawians is HIV infected, it is disturbing that HIV testing is being viewed as not indicated for persons seeking health-care. ${ }^{2}$ On the other hand, a clinician may have given this reason in reference to patients who are already known to be sero-positive or have recently being tested. It should be reinforced that testing is not necessary in such cases.

Lack of a testing facility was the fourth most common reason listed for not offering HIV 
48 African Journal of Reproductive Health

testing to patients. As HIV test availability is improving in Malawi, clinicians must be informed of options. A clinician whose facility does not have its own testing centre might send blood samples to another centre for analysis or refer patients. Establishment of additional testing centres, currently being done under the auspices of the Global Fund for AIDS, Tuberculosis and Malaria, should facilitate improved testing rates. In addition to notification about new facilities, clinicians should be periodically updated on all available testing centres. This can be incorporated into medical training and continuing medical education.

Furthermore, alternative methods, such as saliva tests, may eventually be available for screening. ${ }^{36}$ Although confirmatory testing would still be necessary, the use of alternative methods could simplify the screening process. ${ }^{37} \mathrm{New}$ information about screening methods should be incorporated into medical education so that clinicians can be informed about them, thus improving their counselling ability.

Lack of time, reported by $28.9 \%$ of respondents, was the fifth most common reason for not offering HIV tests to patients. Use of ancillary services, such as in-house counsellors or voluntary counselling and testing centres, will save the clinician time during medical visits while simultaneously providing avenue for the patient to undergo testing. However, justifying omission of HIV testing on the basis of time constraints suggests that they do not see it as a priority. Besides teaching clinicians how to improve their time management, clinicians must understand that HIV is a worldwide pandemic for which testing is of utmost importance.

Information from this study could be used to develop interventions to improve HIV testing rates in Malawi. However, the applicability of this study is limited by several factors. This survey sought only to identify general reasons clinicians may not offer HIV testing to patients. Charac-terisation of more specific aspects of the reasons was not undertaken. This needs to be done before the results can be used to design specific interventions.

Given the $54.3 \%$ response rate, our sample may not be representative of all clinicians in Malawi. Furthermore, the survey population was limited to clinicians listed in the Medical Council of Malawi registry and those identified by the investigators. Resultant nonrandom non-response could bias results. Fortunately, age distribution in the sample and surveyed population was similar, and population weighting by profession did not change the relative frequency of responses. Thus, results are likely generalisable to Malawi's clinician population.

Some respondents did not provide answers to all questions. Responses for surveys that did not contain all factors in a particular model could not be considered fit in the model. Since the maximum number of surveys excluded for a particular model was 23 out of 523 (4.4\%), exclusion of these is unlikely to significantly impact results.

Lastly, the wordings used in the survey questionnaire are subject to interpretation by respondents. Question Eleven asked for reasons one "may not have been able to offer an HIV test". Some clinicians may have listed only reasons for not offering an HIV test in the past, while others may have also listed reasons they believed could prevent offering a test even if it was not done so previously. In terms of the possible responses, "HIV testing is not indicated" could refer to patients for whom HIV status was already known or patients for whom HIV status was unknown but whom the clinician felt did not need testing. Further investigations may need to word questions and response options more explicitly.

In conclusion, efforts to improve HIV testing rates in Malawi should include measures to increase HIV testing by clinicians during patient encounters. Such targeted interventions must take into account reasons clinicians do not offer testing 
to their patients.

In this study, several common reasons for not offering HIV tests were identified. Based on these results, it seems most appropriate to develop a general clinician intervention. However, further characterisation of reasons for not offering HIV tests should be performed.

\section{Acknowledgments}

The authors thank the National Research Council of Malawi for funding the project; Blantyre Adventist Hospital for logistical support; and Andrew Likaka, Malangizo Mbewe, Lumbani Munthali and Sandress Msuku for data entry.

\section{REFERENCES}

1. UNAIDS and WHO. AIDS Epidemic Update 2002. Geneva: UNAIDS, 2002.

2. UNAIDS and WHO. Epidemiological Fact Sheet: Malawi. Geneva: UNAIDS, 2002.

3. Chirwa I. AIDS epidemic in Malawi: shaking cultural foundations. Network 1993; 13(4): 21-31.

4. Cuddington JT and Hancock JD. Assessing the impact of AIDS on the growth path of the Malawian economy. J Dev Econ 1994: 43(2): 362-368.

5. Chimzizi RB, Harries AD, Hargreaves NJ, Kwanjana JH and Salaniponi FM. Care of HIV complications in patients receiving antituberculous treatment in hospitals in Malawi. Int J Tuberc Lung Dis 2001; 5(100): 979-981.

6. Glynn JR, Warndoff DK, Malema SS, et. al. Tuberculosis: associates with HIV and socioeconomic status in rural Malawi. Trans R Soc Trop Med Hyg 2000; 94(5): 500-503.

7. Graham SM, Mtitimila EI, Kamanga HS, Walsh AL, Hart CA and Molyneux ME. Clinical presentation and outcome of Pneumocystis carinii pneumonia in Malawian children. Lancet 2000; 355(9201): 369-373.

8. Crampin AC, Floyd S, Glynn JR, et. al. The long-term impact of HIV and orphanhood on the mortality and physical well-being of children in rural Malawi. AIDS 2003; 17(3): 389-397.

9. Valdiserri RO, Janssen RS, Buehler JW and Fleming PL. The context of HIV/AIDS surveillance. J Acquir Immune Def Synd 2000; 25(Supp 2): S97-104.

10. Nachega J. Antiretroviral treatment in developing countries. The Hopkins HIV Report 2002; 14(5): 10-11.

11. Ministry of Health and Population and National AIDS Commission. Treatment of AIDS. Guidelines for the Use of Antiretroviral Therapy in Malawi. First edition. Ministry of Health and Population, 2003.

12. National AIDS Commission. Global Fund grant award to Malawi. Daily Times November 9, 2002: 8.

13. Ministry of Health and Population and National AIDS Commission. Treatment of AIDS. Guidelines for the use of antiretroviral therapy in Malawi. First edition. Ministry of Health and Population 2003.

14. Jamali P. Church pledges antiretroviral drugs. Battle against AIDS rages on. The Weekend Nation. November 9-10, 2002: 11.

15. Kemp J, Aitken JM, LeGrand S and Mwale B. Equity in health sector responses to HIV/ AIDS in Malawi. Regional Network for Equity in Health in Southern Africa. Harare: Equinet, 2003.

16. St Lawrence JS, Montano DE, Kaspryzk D, Phillips WR, Armstrong K and Leichliter JS. STD screening, testing, case reporting, and clinical and partner notification practices: a national survey of US physicians. Am J Pub Health 2002; 92 (11): 1784-1788.

17. Centers for Disease Control and Prevention. Revised guidelines for HIV counselling, testing and referral. MMWR Recomm Rep 2001; 50(RR-19): 1-57.

18. Kine MW and O'Connor KG. Disparity between pediatricians' knowledge and 
African Journal of Reproductive Health

practices regarding performing HIV counseling and testing. Pediatrics 2003; 112(5): e367.

19. Peters V, Liu KL, Doninguez K, et. al. Missed opportunities for perinatal HIV prevention among HIV-exposed infants in 1996-2000, pediatric spectrum of HIV disease cohort. Pediatrics 2003; 111(5 part 2): 1186-91.

20. Jayaraman GC, Preiksaitis JK and Larke B. Mandatory reporting of HIV infection and opt-out prenatal screening for HIV infection: effect on testing rates. CMAJ 2003; 168(6): 679-682.

21. Grimes RM, Courtney CC and Vindekilde J. A collaborative program between a school of public health and a local health department to increase HIV testing of pregnant women. Pub Health Rep 2001; 116(6): 585-589.

22. Lalonde B, Uldall KK, Huba GJ, et. al. Impact of HIV / AIDS education on health care provider practice: results from nine grantees of the Special Projects of National Significance Program. Eval Health Prof 2002; 25(3): 302-320.

23. Wolf MS and Mitchell CG. Preparing social workers to address HIV/AIDS prevention and detection: implications for professional training and education. J Comm Health 2002; 27(3): 165-180.

24. Temmerman M, Ndinya-Achola J, Ambani $\mathrm{P}$ and Piot P. The right not to know HIVtest results. The Lancet North Am Ed 1995; 345(8955): 969-970.

25. Makura ZGC. Competent inadequacy. Cent Afr Med J 1991; 37(2): 67-68.

26. Chambers ST, Heckert KA, Bagshaw S, Ussher J, Birch M and Wilson MA. Maternity care providers' attitudes and practices concerning HIV testing during pregnancy; results of a survey of the Canterbury and upper South Island region. NZ Med J 2001; 114(1144): 513-516.

27. Gibney L, Wade S, Madzime S and Mbizvo M. HIV testing practices of Zimbabwean physicians and their perspectives on the future use of rapid on-site tests. AIDS Care 1999; 11(6): 663-673.

28. Troccoli K, Pollard H 3rd, McMahon M, Foust E, Erickson $\mathrm{K}$ and Schulkin J. Human immunodeficiency virus counseling and testing practices among North Carolina providers. Obstet Gynecol 2002; 100(3): 420-427.

29. Sweat M, Gregorich S, Sangiwa G, et. al. Cost effectiveness of voluntary HIV-1 testing in reducing sexual transmission of HIV-1 in Kenya and Tanzania. Lancet 2000; 356(9224): 113-121.

30. The Voluntary HIV-1 Counseling and Testing Efficacy Study Group. Efficacy of voluntary HIV-1 counseling and testing in individuals and couples in Kenya, Tanzania, and Trinidad: a randomized trial. Lancet 2000; 356(9224): 103-112.

31. Gibney L, Wade S, Madzime S and Mbizvo M. HIV testing practices of Zimbabwean physicians and their perspectives on the future use of rapid on-site tests. AIDS Care 1999; 11(6): 663-673.

32. Muula AS and Broadhead RL. The first decade of the Malawi College of Medicine: a critical appraisal. Trop Med Int Health 2001; 6(2): 155-159.

33. Groves RM and Couper MP. Nonresponse in Household Interview Survey. New York: John Wiley and Sons, 1998.

34. Rosner B. Fundamentals of Biostatistics. Fifth edition. Pacific Grove: Duxbury, 2000.

35. Data Analysis Division. S-PLUS 6.0 for UNIX. Seattle: Mathsoft Inc, 2000.

36. Luo N, Kasolo F, Ngwenya BK, Du Pont HL and Zumla A. Use of saliva as an alternative to serum for HIV screening in Africa. S Afr Med J 1995; 85(3): 156-157.

37. Samuel NM, Chandrasekaran $A$ and Paul SA. Detection of antibodies to HIV-1 in serum and saliva. I Assoc Phy India 1997; 45(4): 280-282.

African Journal of Reproductive Health Vol. 9 No.3 December 2005 